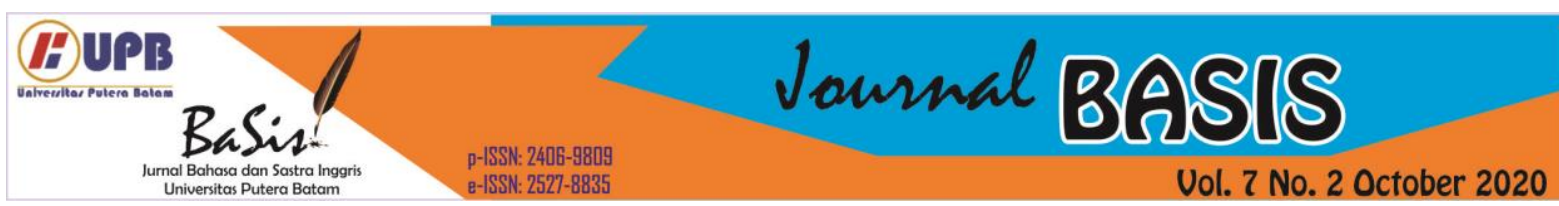

\title{
GOOD HOOK AS ATTENTION GRABBER IN EFL STUDENT'S ESSAYS: A REVIEW FROM READER'S PERSPECTIVE
}

\author{
Zia Hisni Mubarak ${ }^{1}$ \\ Universitas Putera Batam (UPB), Batam, Indonesia \\ Zia.Hisni@puterabatam.ac.id ${ }^{1}$ \\ Gaguk Rudianto ${ }^{2}$ \\ Universitas Putera Batam (UPB), Batam, Indonesia \\ Gaguk@puterabatam.ac.id ${ }^{2}$
}

\begin{abstract}
This article provides a review from the reader's point of view of essays' hook written by EFL students in Putera Batam University. The purpose of this study is to provide an overview of the effectiveness of the opening sentence which is able to attract readers to read the entire essay or perhaps ignore it altogether. By acting as a reader, the researcher then provides a review of the opening sentence in the introductory paragraph. This research uses descriptive research method. The data is taken from the student's writing task. The data are then grouped based on how to make a good hook and analyzed based on how to write a good hook. The researchers act as the reader and uses their point of view to judge an interesting hook. The results obtained from this study are 23 data hooks using questions, 17 data hooks with interesting observations, 11 data hooks had unique scenarios, 4 data hooks using famous quotes and 3 data with statistics. Furthermore, the remaining 6 data were identified not to write hooks using these five methods. From this review, it can be concluded that writing hooks is not as easy as it seems, because to attract readers' interest the writer should be able to see the hook from the reader's point of view.
\end{abstract}

Keywords: a good hook, attention grabber, EFL students, essays

\section{INTRODUCTION}

Students are often faced with the task of writing essays as part of their assignments while studying at university. Writing for some students become a burden for them because many of them do not feel confident in what they have to write. This insecurity is followed by fears such as fear of making mistakes when writing and lack of initiative in developing their writing ideas. This concept is commonly found in learning conditions, especially when learning languages in the EFL (English as a Foreign Language) context. As Lee, Fitria, \& Ginting (2019) stated several conceptions of student learning in Indonesia such as fear of mistakes, lack of initiative and lack of communication skills in writing. What they stated was a common phenomenon that occurs in most students in Indonesia where in the context of speaking they find it easier to organize ideas than to write them down. 
Writing is not something that is easy to do. Writing is one of the skills in English which is one of the most difficult skills to master. Mubarak \& Rudianto (2017) stated that students assume writing as one of the most difficult skills to master. Then a question may arise, why is writing difficult? Maybe this phenomenon can occur because writing requires a more complex thinking process than if we are talking.

Writing an essay is part of academic writing. It must be noted that in writing an essay, students must know the parts of the essay such as the introduction, the content and the closing section. In particular, the opening paragraph consists of a hook, a connecting sentence and a thesis statement. A good hook in an essay will determine whether or not the reader will read the essay until the last paragraph. To write a good essay, students must make sure that their essay is well connected. (Folse, MuchmoreVokoun, \& Solomon, 2002).

In addition, the characteristics of EFL students in Batam are studentworker type. This means that most students work in factories and at the same time they have class as well in the university. This condition sometimes makes the teaching and learning process a challenge. In writing subjects, students need to learn how to write good essays with a good hook.

\section{LITERATURE REVIEW}

\subsection{The writing process and essay writing}

Writing is the process of conveying the writer's ideas. To express ideas in mind, the writer must often practice his/her writing skills. Before writing, it is better that the writer has to read every related information in order to fill the background knowledge. The writer can read books, magazines, newspaper and other related literatures.
From reading, the writer will get many ideas that will be the source of the writing. It can be said then writing is a process or personal action in which the writer takes ideas and turns them into topic (O’Malley \& Pierce, 1996).

Coulmas (2003) defined writing as language recording system through visible marks, the activity of putting such a system to use and its result (texts). Furthermore, writing is then defined as a certain form of a script style writing. Writing is also assumed as an artistic composition, where in writing, the art of composing text is included as part of writing. Writing is also associated with a professional job where writers can become famous just by writing such as J.K. Rowling, who successfully wrote the best-selling fiction book.

Writing is also part of the learning process. It is always used as a means of conveying information and reports on observations. Murray \& Moore (2006) explained that writing is a form of manifestation of the professional learning process and as an ongoing process that involves reflection, improvement, development, progress and fulfillment. Writing is a long process and has different stages in each process.

Taylor (2009) explained that writing is the actualization of grammar so that writing requires a good ability to represent ideas. Brown \& Abeywickrama (2010) had also coined the formulation that writing is basically a way to represent speech using the grammatical and lexical features of the language. It can be said then, grammar is important in process of writing from beginning to the end.

Oshima \& Hogue (2006) mentioned that the type of writing at university is academic writing. They explained that academic writing is different from other types of writing such as personal writing, literary writing, journalistic writing, business writing and 
so on. Swales \& Feak (2004) stated that students in university face many writing assignments related to their major. Not only doing written assignments such as reports, summaries, and so on, but students are also required to be able to master the academic writing required to write a thesis as a final report of their study. One example of an academic writing is an essay writing.

Writing an essay is one part of the assignments given at university. Essays are usually used to measure the level of understanding of students in a topic. Writing an essay is a long process, because writing cannot be finished all at once. The essay writing stages can be started from understanding the title or topic, look for the most suitable reading material and choose the relevant areas to the topics. Then make some notes using the ability to summarize and paraphrase. After that, determine the plan or structure of the essay, write the main body of the essay with an introduction and a conclusion. The final process can be done by involving other people who are more skilled, namely by doing proof-reading (Bailey, 2003).

\subsection{Part of an essay and hook}

The essay consists of three parts, namely the introduction, the body and the conclusion. When writing an essay, students have to be able to present this basic outline of the essay. Introduction and conclusion paragraphs are usually written in one paragraph. Meanwhile, for the body of the essay, it is usually written in one to four paragraphs. For introductory paragraph, it usually consists of three parts such as hook, connecting information and thesis statement (Bailey, 2003, 2006; Folse et al., 2002).

Hook is a part of introduction. Introduction is the first part of an essay, usually in the first paragraph. Hook has function as attention grabber where this sentence will lead reader to read the whole essay. Hook is also called as an opening statement from an essay. Writing a good hook is not easy. It requires a great deal of thought and practice. There are many different ways to write a hook. One common way to write a hook is to ask a question. The second way to write a hook is to use an interesting observation. The third way to write hook is using a scenario. Sometimes to write a hook, the writer uses a famous quote. The last way as an effective way to write a hook is by using a statistic (Folse et al., 2002).

Then, the hook and thesis statement are connected by connecting information. This connecting information functions as a link like a bridge connecting two sides. The writer usually writes three to five sentences that help connect the reader and the topic. These sentences can be background information about the topic or they can be examples. The last part is the thesis statement which serves to explain what will be revealed in the body of the essay. Basically, there are two kinds of thesis statements, stated and implied thesis statement (Folse et al., 2002).

The body of the essay can consist of several paragraphs according to the purpose of the essay. Each paragraph is written in a good paragraph structure such as in a paragraph, there must be a topic sentence, supporting sentences and concluding sentence. At the end, it is the closing section which contains conclusions. In writing this conclusion, an opinion that is the conclusion of the essay can also be included (Folse et al., 2002; Folse, Muchmore-Vokoun, \& Solomon, 2010).

Paragraphs are very important to study because they are the building blocks of an essay. The paragraph is the basic unit of organization in writing in which a group of related sentences develops one main idea. Paragraph is also 
defined as a set of sentences about a topic consisting of at least five sentences or ten sentences in length. In other words, the number of sentences doesn't matter; however, the paragraph should be long enough to develop the main idea clearly. A paragraph may stand on its own. It can also be a part of a longer piece of writing such as a book chapter or essay (Oshima \& Hogue, 2006; Zemach \& Rumisek, 2003, 2005). Paragraphs have three main structural parts (Zemach \& Rumisek, 2003, 2005): the topic sentence, the supporting sentences, and the closing sentence.

Greetham (2008) defined supporting sentences as development and the evidence as closing sentence. The topic sentence states the main idea of the paragraph. This not only mentions the topic of the paragraph, but also limits the topic to one or two areas that can be fully discussed in one paragraph. This specific area is called the controlling idea. Supporting sentences develop the topic sentence. That is, they explain the topic sentence by providing reasons, examples, facts, statistics, and quotes. Supporting sentences are also divided into two categories such as supporting points and supporting details. The concluding sentence marks the end of the paragraph and leaves the reader with important points to remember.

\section{RESEARCH METHOD}

The design of this research is a descriptive research which involved the collecting of the data in order to answer the research questions concerning the current status or phenomena (Arikunto, 2010). The review of introductory paragraph is analyzed by using qualitative analysis since this approach was aimed at describing things as the way they are (Gay, Mills, \& Airasian, 2009). The unit analysis of this research was the data taken from students' essay since the concept of unit of analysis is related to where do the data collected from (Satori \& Komariah, 2011). The data are collected from 16 students of Universitas Putera Batam as EFL students. The data are the student's essays from their final assignments in 2019 and it is used as the primary sources of this research. Each student wrote four kinds of essays namely narrative, cause-effect, comparison and argumentative essays.

Analyzing the data is a process to interpret and analyze the data from the first step data is obtained in the field. Analyzing the data is done by the descriptive analysis and the conclusion is described from the description of the data. There are some steps to analyze and evaluate the paragraph structure of introductory paragraph in students' essays. First of all, grouped the students' writing based on the ways of writing a hook. The researcher read the text and analyzed the hook whether it presented the indicators of writing a good hook or not. Then, researcher re-read the data again and analyzed the introductory paragraph whether it presented the indicators of paragraph structure or not.

\section{RESULT AND DISCUSSION}

To analyze a good hook, it can be done in several different ways such as asking a question, using an interesting observation, using a unique scenario, using a famous quote, and using a statistic. The data is taken from EFL student's essays submitted as final assignment. The data were taken from 16 students who wrote four types of essays; narrative, cause-effect, comparison and argumentative essays. The discussion is then divided into five categories of how to write a good hook and one category that fails to represent all of these categories.

From the 64 data, each introductory paragraph is analyzed and 
the analysis is then focused on the opening sentence as a hook that serves to attract the reader's attention. The results of this study show that from 64 data there are about 23 data that represent hooks using questions. In the second order, it is found 17 data representing hook writing using interesting observations. Meanwhile, there were 11 data that represented hook writing using unique scenarios. The next sequence is found as many as 4 hook sentences using famous quotes. For the last category, only 3 data were found related to hook writing using statistical data. However, it is unfortunate that there are about 6 data that do not represent a good way of writing a hook so that it is identified as a failed attempt to write a hook.

\subsection{Writing a hook by asking a question}

From 64 essays written by $16 \mathrm{EFL}$ students, there are 23 data which have interesting hook by using the first criteria. One of the way to write a hook is by asking a question. This category seems to be the common way where researcher found many students wrote their hook by asking a question. Probably this category is the easiest way to attract the reader attention, but in the example below asking question sometimes could not be so effective. Let us see the example of Data 5.

\section{What would you do if you left the house in hot weather and forgot to use sunscreen?...}

This data is the first sentence of the paragraph where the writer use question to catch the reader's attention. It is the hook. The question now is, are you as the readers interesting to read this hook? The answer could be yes or no. The writer tried to hook the reader's attention but it could be not so effective. If the writer write the hook by using statistic for example, it would be interesting to be read. See the revision below.

For about $75 \%$ of human
population in the world is
never using sunscreen or even
does not know about
sunscreen...

Regarding the example above, the hook is more interesting and it will grab the readers' attention. Why this hook is interesting, because this hook presents statistic numbers and facts as benefit information for the readers. Finally, both hooks are acceptable even though it is better if the writer presents statistic. But, somehow the writer has done a good thing by asking a question to grab the reader's attention.

Another example for this category is data number 7 . The writer asks a question and plays with readers emotional to catch the reader's attention. The attempts to catch the reader's attention in this data is more powerful.

How does it feel when
you see a picture of your father
with another woman who is not
your mother? Or how does it
feel to have to call someone
else your mother while she is
not your biological mother? ...

By observing the opening sentence above, it is kind of a good hook. The writer asks the readers twice and it becomes powerful bound between the readers and the text. The readers who has the same experience will say the same and their support to the writer is by reading the whole text. Meanwhile the readers who are not affected by this condition, they will have deep curiosity to know the more about this information.

The same case as previous example can be seen in other data as 
number 46 which has good hook as well. The data below makes an effort to grab the reader's attention.

Do you know that sunlight side effect can bring skin cancer? If you exposed your skin under the sun too long you would not only getting darker, the side effect of sunlight could also bring a serious problems to your skin...

As it is written in the data above, the question is strongly sensitize the readers about the effect of sunlight. The readers know that sunlight is useful for life but from this hook the readers get another perspective that sunlight has side effect. Of course, the readers will consider to read the whole essay as a beneficial information. So, it can be said that this hook is interesting and definitely will catch the reader's attention.

Writing a hook by asking a question is one way to attract the reader attention so that the reader will read the rest of the essay. This way of writing hook seems to be the most preferred choice by the student writers. This is because asking question is simple and aroused curiosity of the reader to know the next information.

\subsection{Writing a hook by using an interesting observation}

The second category of writing a hook is using an interesting observation. There are 17 data written by the students by using an interesting observation. This category is written from the writer's observation and using his/her point of view. For the first example, see data 6 below.

Most people will check the gadget when they wake up...
From the hook above, the writer had conducted an observation related to the topic of his/her essay. This hook sentence is a kind of attention grabber where the readers is shocked about the fact presented in the hook. The readers will probably have a question in their mind such questions; is this real? Is this happening now? Is this really happening to the society now? To answer their questions, they will go to the next paragraph and find out the information by reading the rest of the essay. It is concluded that this hook is kind of a good hook that draw attention from the readers.

Similarly, other interesting observations are also present in other data such as data 46. This data provides a good hook to catch the readers' attention. The data is served below.

\section{Human habits change over time...}

The readers may ask several questions in their mind such as what is the cause of it. How it is changing? What is the previous habit? What is the effect of changing habits? This hook is a kind of interesting observation where the writer gave his/her opinion through the sentence about phenomenon that he/she observed. The readers who have a lot of questions in their head are likely to continue reading to the end of the essay. Until their questions are answered, they will not stop looking for answers. After finding the answer, then they are satisfied with the information they have received.

Writing the opening sentence by using interesting observations can be an alternative way of writing a good hook. Before writing this hook, the writer should know the development of the issues that will be raised as topics in the writing so that the hook can represent interesting observations. 


\subsection{Writing a hook by using a unique scenario}

Another great way to write a good hook is to use a unique scenario. Based on the data grouping that has been done, this third method is the third most favorite way to write a hook where of the 64 existing data, there are 11 hook sentence data written using a unique scenario. Writing hook sentences using unique scenario is more often found in narrative essays. An example can be seen in the data 1 below.

Learning something new can be a scary experience. One of the difficult things I have ever had was learn how to swim. I was always afraid of the water...

Referring to the data above, the hook is described using a unique scenario, namely by giving a little picture of fear. The writer's fear of learning something new is clearly illustrated by the first hook sentence. The writer later described that he/she had difficulty learning to swim and had a fear of water. This unique scenario will make an impression on the readers and they will have to read the essay to the end to find out what the story is about.

In the next data, we can also see a hook sentence that describes the use of a unique scenario, namely data 10 . In the paragraph below, it can be seen that the writer uses a unique scenario to attract the reader's attention, namely comparing humans to plants. For more details, consider the following data 10 below.

Human is very similar to a flower. We grow up slowly, bloom and slowly decay away...

Readers' questions will arise after reading the hook sentence above, what do humans have in common with flowers?
From this hook, the readers want to know what happened to the writer and they have to find the answer in the essay. By reading the whole essay, the writer is success to hook the readers or to attract their attention.

If we pay attention to the next data, which is the $57^{\text {th }}$ data, besides we find a unique scenario that is described in the hook sentence, then we will also wonder; what is wrong with the writer? Why did he nearly die? What kind of toothache made the writer nearly die? Pay attention to the data below for more details.

In the year of 2018, death almost says hi to me. Well, I had a toothache and I went to dentist to solve my tooth's problem...

If we look at the first sentence, the readers will become interested in what kind of experience befell the writer. They will read the rest of the story for sure to find out the answers toward questions they have in mind. It can be said then that writing a hook using a unique scenario is one of the effective ways to attract the readers' attention.

\subsection{Writing a hook by using a famous quote}

The fourth way to write a hook is by using a famous quote. This way seems to be one of the easiest way to write a hook, but from 64 data there are only 4 data which using a famous quote as a hook. This condition has its own reason because probably the writers were not familiar with quotes or it could be the readers who are not familiar with the quotes. Now consider the data 45 below.

“Don't laugh too much, don't be so overjoy. You would end up crying hard later" have you ever heard that advice 
before? My grandmother constantly lectures me with that...

The writer uses a wise quote as a hook. By looking at the data above, we are given a very valuable lesson. We are reminded not to overdo it, especially during good times. This advice is the value of a culture that is still being maintained. By reading the hook sentence above, we as readers will be interested in reading the text to the end.

Another example on this way of using a famous quote to write a hook is data number 59. From this introductory paragraph, the hook is categorized as an interesting hook where the writer of this hook realized that by using famous quote the readers will be interested in reading the whole text. For a better understanding, see the example of the opening sentences below.

\section{"You are not that worth if you don't have the looks."...}

From that hook the readers is sensitized about the common things happened in our society now. Someone is valued because of the look but if they do not have that look, the treatment will be different. Take a sample from someone who wears fancy cloth and ride a car compare to someone who wears casual cloth and take a bus. The treatment from society will be different, even though the fact sometimes the second criteria is wealthier than the first criteria. From this point of view, the readers probably will read the whole essay to know what is going on to the society right now. The readers want to know the point of view from the writer about this phenomenon.

By analyzing the fact from some examples discussed above, it could be concluded that writing a hook by using a famous quote is one way to write a good hook. By presenting a famous quote as a hook, the writer is intended to grab the reader's attention. This intention is successfully attract the reader's attention where the writer is success to arise reader's curiosity.

\subsection{Writing a hook by using a statistic}

The last way of writing a hook is by using a statistic. This kind of writing a hook is considered as one effective way to grab the reader's attention. The statistic writing can be by using percentage, numbers, and others. Of all the ways to write a good hook, this method is the one least chosen by informants to write hooks that can attract readers. Consider an example of the opening sentences below.

World's problem that
never have solved until now is
bullying. About million
children or adult has suicide
committing because of
bullying...

The data above is taken from data 23 . From the hook, there is a word million which indicates the amount numbers of statistic calculation. This statistic number becomes powerful word that presents facts about what is happening to world according to the writer. By presenting statistic, the readers will gain a new information about the fact of what happening around them. This kind of opening sentence will truly attract the reader's attention and as its effect, the readers will continue to read the rest of the essay.

Another example is the essay number 48. In this introductory paragraph, the writer talks about dangerous effect of smoking. By presenting the statistic number, the writer hopes the readers will gain awareness to quit smoking.

Smoking is the biggest cause of preventable deaths in 
England, accounting for nearly

80,000 deaths each year...

By looking at the hook sentence above, there is number " 80.000 " to show a statistic calculation. The precise number is actually not presented here, but the writer uses the word "nearly" to describe how big the case is. Through this fact then, the readers will be shock to know the fact that total deaths in England in a year is nearly that numbers. What about other countries? This fact will drive the readers to read the whole essay to gain more information about effect of smoking.

The last data to be presented in this analysis is data from essay 63 . In the introductory paragraph, the hook are written in some sentences as interesting opening statement of the essay. Take a look the example of introductory paragraph from essay 63 below.

I am the one who has bipolar disorder oftentimes must explain how it feels to be bipolar sufferer. Almost ten to twelve percent bipolar sufferers die wherefore their own hands. According to the data from $\mathrm{WHO}$ in 2016, there are about 60 million people in the world suffer from bipolar disorder...

From the second sentence, there are words of "ten to twelve percent" which is represented the statistic numbers. In the third sentence, the writer formulated the statistic numbers by using data like years "2016" and the total people who suffer from this, that is, 60 million people. This fact brings the readers to the phenomenon that happened around them. By looking at statistical fact, it is as if the reader is awakened from a dream to see a shocking reality. Of all this, the reader will then be sure to read the next information contained in the essay.

Writing hooks using statistics is a great way to attract readers' attention. Statistic writing provides information such as facts and opinion needed by readers. Although this hook writing by using statistics is the least used method, the result of this study cannot be generalized that this method is a difficult way to write hooks. In fact, this method is one of the most effective ways to attract readers.

\subsection{Fail writing a hook}

There are some data from 64 data of essays from student's writing that are fail to meet a good criteria of writing a good hook. These data appear due to the possibility that they represent various causes, such as students' lack of understanding of how to write a good hook or it could be due to their lack of attention when studying. Consider the example of writing a hook below.

$\quad$ Marriage is an
important thing for everyone.
We can live with someone that
we loved for the rest of our
life...

The writer has tried to write a good hook but it still fails. If the writer can write a more engaging hook, then this introductory paragraph will grab the reader's attention. The writing of the opening sentence as a hook in the paragraph above does not meet the five ways of writing a good hook. What if the hooks in the data above is were added or changed to something like this, "Imagine if the marriage did not exist, what would happen to the social order? Can humans love each other?" By reading this opening sentences, the reader will likely be interested in reading the rest of this story. 
In some other data, it shows a failure to write a good sentence so that it is difficult to identify as an opening sentence. Data 25 and data 28 are examples of the current discussion. These data can be seen below.

The first thing to do when seeing a ghost. This is my first time seeing a ghost...

From the data 25 above, it can be seen that the opening sentence which functions as a hook is not a complete sentence. It is more suitable if it is referred to as a phrase or clause. If the hook sentence above is fixed; The first thing most people will do when they see a ghost is run at full speed without a definite direction. This hook is made with interesting observational criteria.

However, the writer can also write hooks with other criteria such as using unique scenarios; Suddenly a white shadow flashed before my eyes and I was silent for a moment without moving. The shadow was getting closer to me quickly, as if it was going to pounce on me. I felt like I was hit by a big wave that made me have to run fast. This scenario will make the reader curious about what happened to the writer. Is the experience experienced by the writer is a true story or just an illusion. From this point, the reader will then be interested in reading further about this story.

Then data 28 below also has the same problem as the previous data, namely the opening sentence is not a complete sentence but more like a phrase or clause. Look at the opening sentence in paragraph below for more details.

Enjoyment of life in the suburbs. Choosing to live on the edge of the city is not unusual...
The hook sentence is "Enjoyment of life in the suburbs". The hook above is an incomplete sentence. If the opening sentence of the paragraph is revised, then the paragraph will have a better hook. Some examples of hook revision using famous quotes and statistics can be seen from the following recommendations. Firstly, by using a famous quote, the writer can write a hook like "The suburbs: signs of life, but no proofs". Readers will be curious about why the writer used the quote and from which point of view the quote has an impact on the reader. They will also be curious about the meaning of the quote used by the writer.

Furthermore, the hook sentence can also be revised by using statistics, for example: "More than 50\% of the population in the cities choose to live in suburban areas. By using statistics, readers are presented with data and facts about an issue that is being discussed. From here, readers will be interested in reading the entire essay because of their curiosity about the data presented in the hook sentence.

Writing hook sentence is actually not easy because what we find interesting may not necessarily appeal to the reader. As writer, we may tend to feel that what we have written is the most perfect result. Consequently, what we produce becomes the most perfect writing without the slightest error. Apart from knowing how to write a good hook, the writer must also be able to see from the reader's point of view. So that when a writer puts himself in the position of a reader, it will be easier for the writer to correct his/her writing, including whether the hook is interesting or not.

\section{CONCLUSION}

This study resulted in several findings that have been discussed in the results and discussion section. So that the researchers then draw conclusions from 
the findings obtained. The first conclusion is that from the 64 data reviewed, there are 6 data that fail to represent a good and interesting hook. Meanwhile, 58 data shows good and interesting hook writing based on the criteria of good hook writing. In the first criterion, the hook is written by asking questions and from this method 23 data are found. The second way to write hooks is to write interesting observations and from this second method 17 data are found. Furthermore, 11 data were found to write hooks using unique scenarios. The fourth way is to use famous quotes and from this method we get 4 data that use it to write hooks. The last is to write a hook using statistics and from this method we get as much as 3 data.

The second conclusion is the findings that provide an overall assessment of the writing of hooks written by the 16 students. The researcher then concluded that writing hooks was not easy. Moreover, writing a hook that is able to attract readers so that they are impressed with the sentences presented and read the essay to the end, is a challenge that must be learned by the students. In order to write a good hook, students are asked to follow the five ways of writing hook and place themselves as readers. By examining hooks using readers' point of view, they are able to reflect their hook writing whether it is attracting the readers' attention or not. Finally, further research are recommended to investigate various problems in the essay such as how the hook sentences have connection to the thesis statements and so forth.

\section{REFERENCES}

Arikunto, S. (2010). Prosedur penelitian: Suatu pendekatan praktik. Jakarta: Rineka Cipta.

Bailey, S. (2003). Academic writing: A practical guide for students. New York: Routledge Palmer.

Bailey, S. (2006). Academic writing: A handbook for international students. New York: Routledge.

Brown, H. D., \& Abeywickrama, P. (2010). Language assessment: principles and classroom practices (Second Edi). San Fransisco: Pearson Education.

Coulmas, F. (2003). Writing Systems: An Introduction to their linguistic Analysis. New York: Cambridge University Press.

Folse, K. S., Muchmore-Vokoun, A., \& Solomon, E. V. (2002). Great essays (2nd ed.). Boston: Heinle Cengage Learning.

Folse, K. S., Muchmore-Vokoun, A., \& Solomon, E. V. (2010). Great writing 2: Great paragraphs (Third Edit). Boston: Heinle Cengage Learning.

Gay, L. ., Mills, G. E., \& Airasian, P. (2009). Educational research: Competencies for analysis and applications. New Jersey: Pearson Education.

Greetham, B. (2008). How to write better essays. New York: Palgrave Macmillan.

Lee, B., Fitria, A., \& Ginting, H. (2019). Analysing literacy and other psychological tendencies using linguistic profile in English expressive writing: Are students able but unwilling to write? Indonesian Journal of Applied Linguistics, 9(1), 27-37. https://doi.org/10.17509/ijal.v9i1.12 698

Mubarak, Z. H., \& Rudianto, G. (2017). Cooperative integrated reading and composition (CIRC) technique in writing subject of EFL context. In Proceeding of the Sixth International Conference on Languages and Arts (ICLA 2017) 
(pp. 41-46). Padang: Atlantis Press. https://doi.org/10.2991/icla17.2018 .8

Murray, R., \& Moore, S. (2006). The handbook of academic writing: A fresh approach. New York: McGraw-Hill Education.

O’Malley, J. M., \& Pierce, L. V. (1996). Authentic Assessment for English Language Learners: Practical Approaches for Teachers. Virginia: Addison-Wesley Publishing Company.

Oshima, A., \& Hogue, A. (2006). Writing Academic English: The Longman Academic Writing Series Level 4. New York: Pearson Longman.

Satori, D., \& Komariah, A. (2011). Metodologi penelitian kualitatif. Bandung: Alfabeta.
Swales, J. M., \& Feak, C. B. (2004). Academic writing for graduate students: Essential tasks and skills. (C. G. Madden \& J. M. Swales, Eds.) (Second Edi). Michigan: The University of Michigan Press.

Taylor, G. (2009). A student's writing guide: How to plan and write successful essays. Cambridge: Cambridge University Press.

Zemach, D. ., \& Rumisek, L. . (2003). College writing: From paragraph to essay. Oxford: Macmillan Publisher Limited.

Zemach, D. ., \& Rumisek, L. . (2005). Academic writing: From paragraph to essay. Oxford: Macmillan Publisher. 